\title{
Genetic and genome-wide transcriptomic analyses identify co-regulation of oxidative response and hormone transcript abundance with vitamin $\mathrm{C}$ content in tomato fruit
}

Viviana Lima-Silva', Abel Rosado ${ }^{1}$, Vitor Amorim-Silva ${ }^{2}$, Antonio Muñoz-Mérida ${ }^{3}$, Clara Pons ${ }^{4}$, Aureliano Bombarely ${ }^{5}$ Oswaldo Trelles ${ }^{3}$, Rafael Fernández-Muñoz ${ }^{6}$, Antonio Granell ${ }^{4}$, Victoriano Valpuesta ${ }^{1}$ and Miguel Ángel Botella ${ }^{1,7^{*}}$

\begin{abstract}
Background: L-ascorbic acid (AsA; vitamin C) is essential for all living plants where it functions as the main hydrosoluble antioxidant. It has diverse roles in the regulation of plant cell growth and expansion, photosynthesis, and hormone-regulated processes. AsA is also an essential component of the human diet, being tomato fruit one of the main sources of this vitamin. To identify genes responsible for AsA content in tomato fruit, transcriptomic studies followed by clustering analysis were applied to two groups of fruits with contrasting AsA content. These fruits were identified after AsA profiling of an F8 Recombinant Inbred Line (RIL) population generated from a cross between the domesticated species Solanum lycopersicum and the wild relative Solanum pimpinellifollium.

Results: We found large variability in AsA content within the RIL population with individual RILs with up to 4-fold difference in AsA content. Transcriptomic analysis identified genes whose expression correlated either positively (PVC genes) or negatively (NVC genes) with the AsA content of the fruits. Cluster analysis using SOTA allowed the identification of subsets of co-regulated genes mainly involved in hormones signaling, such as ethylene, ABA, gibberellin and auxin, rather than any of the known AsA biosynthetic genes. Data mining of the corresponding PVC and NVC orthologs in Arabidopis databases identified flagellin and other ROS-producing processes as cues resulting in differential regulation of a high percentage of the genes from both groups of co-regulated genes; more specifically, 26.6\% of the orthologous PVC genes, and $15.5 \%$ of the orthologous NVC genes were induced and repressed, respectively, under flagellin22 treatment in Arabidopsis thaliana.

Conclusion: Results here reported indicate that the content of AsA in red tomato fruit from our selected RILs are not correlated with the expression of genes involved in its biosynthesis. On the contrary, the data presented here supports that AsA content in tomato fruit co-regulates with genes involved in hormone signaling and they are dependent on the oxidative status of the fruit.
\end{abstract}

\footnotetext{
*Correspondence: mabotella@uma.es

${ }^{1}$ Instituto de Hortofruticultura Subtropical y Mediterránea, Universidad de

Málaga-Consejo Superior de Investigaciones Científicas (IHSM-UMA-CSIC),

Departamento Biología Molecular y Bioquímica, Universidad de Málaga,

29071, Málaga, Spain

${ }^{7}$ Departamento de Biología Molecular y Bioquímica, Universidad de Málaga,

Málaga, Spain

Full list of author information is available at the end of the article
} 


\section{Background}

L-ascorbic acid (AsA; vitamin C) is essential for most of the living plant tissues. In addition to its known function as an antioxidant, AsA has important roles in plant cell growth and expansion, photosynthesis, and hormonal regulation [1-3]. Humans are unable to synthesize AsA due to mutations in the enzyme L-gulono-1,4-lactone oxidase (GLDH) that catalyzes the final step of its biosynthesis, and as consequence need to incorporate AsA through the dietary consumption of fresh fruits and vegetables (4). Although AsA deficiency is not a current problem in developed countries, it is recognized that high AsA dietary consumption has important health benefits for the consumer, and an increased intake of AsA has been associated with a decreased incidence of several important human diseases and disorders [4-6].

So far, the study of genes regulating AsA content in plants has been tackled mainly through the use of reverse genetics targeting AsA biosynthesis and recycling genes [7-19]. Even though classical genetic approaches has resulted in the cloning of genes responsible for complex traits [20,21], and several QTLs have been identified for AsA, yet the genes underlying these QTLs need to be determined $[22,23]$. This is likely because identification of the gene responsible for a QTL is timeconsuming and technically demanding especially when the trait requires careful analytical techniques as it is the case for AsA.

In order to overcome these drawbacks, the use of omics approaches to study complex traits have emerged during the past years, and the use of global transcript abundance together with gene cluster analysis has become a useful approach to predict and in some cases assign gene functions [24-27]. The premise behind clustering analysis is that genes having similar expression profiles across a set of conditions (e.g., tissue type, time-point series during development, responses to different stresses) may share similar functions or be involved in similar processes [28]. Still, it is clear that genes with the similar functions do not necessarily share
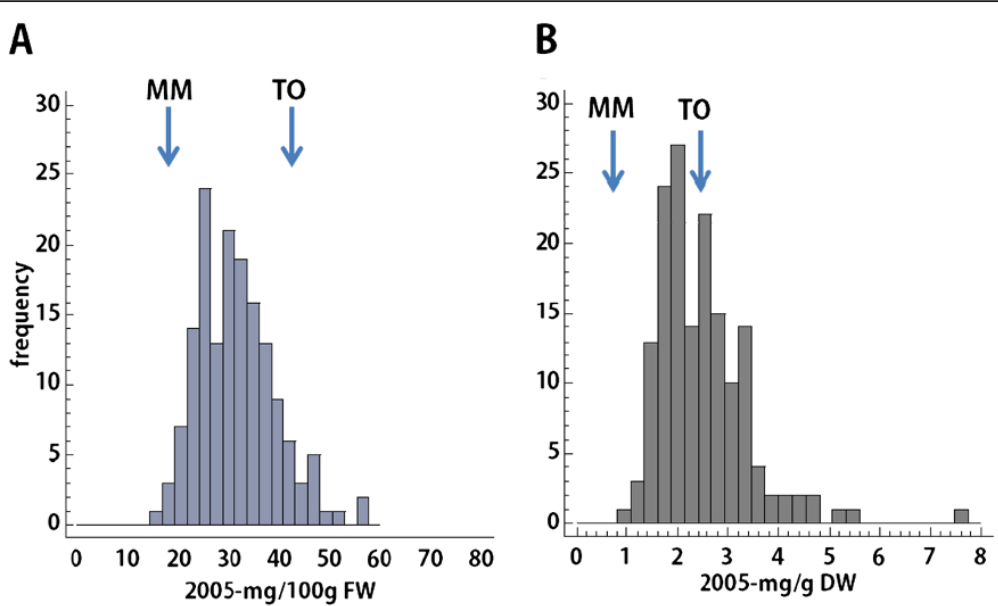

C

D
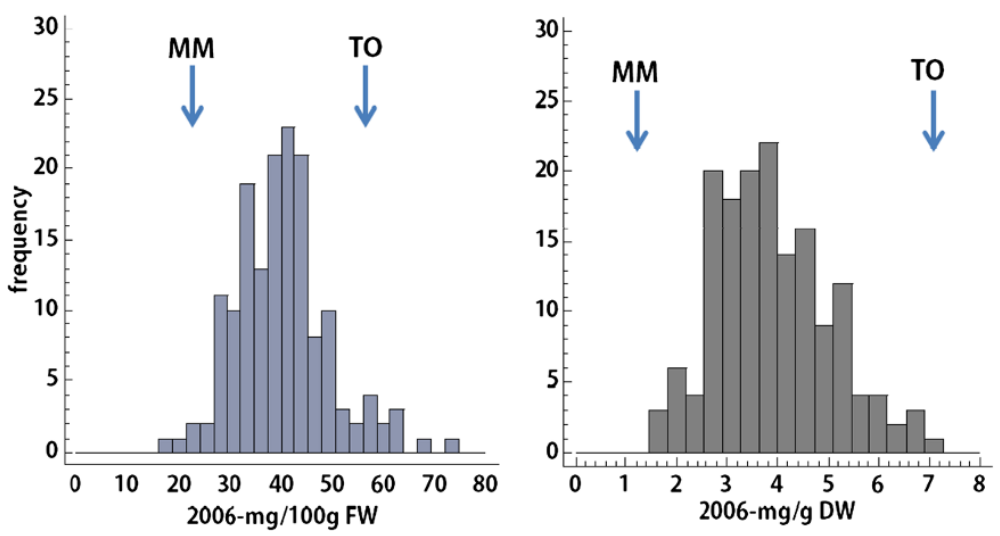

Figure 1 Frequency distribution of fruit AsA content in the 158 RILs during two harvests (years 2005 and 2006). AsA content is expressed as fresh weight (FW; mg/100 g) and dry weight (DW; mg/g). A and $\mathbf{B}$ show AsA content in 2005, expressed as FW and DW, respectively. C and D show AsA content in 2006, expressed as FW and DW, respectively. AsA content in parental S. Iycopersicum cv. Moneymaker (MM) and S. pimpinellifollium acc. TO-937 (TO) lines is indicated with arrows in the plots. 
similar transcriptional patterns, and conversely. Despite this, it has been shown that large numbers of functionally related genes show very similar expression patterns under a relevant set of conditions, especially genes that are co-regulated by common transcription factors, or whose products are components of multiprotein complexes [29]. For these reasons, clustering genes with similar expression patterns may allow to assign putative functions to unknown genes via "guilt-by-association" [29]. In order to accomplish this, several clustering techniques such as hierarchical clustering (HC) [27], selforganizing map (SOM) $[24,25]$, and self-organizing tree algorithm (SOTA) [26] have been successfully used in tomato to identify genes with correlated expression that turned out in the selection of candidate genes for further functional analyses. As an example, the transcriptomic comparison of a S. pennellii introgression line (IL) with its recurrent S. lycopersicum parental line, identified a pectinesterase and two polygalacturonase genes that were associated to the different AsA accumulation in the IL fruits [27].

In this study, several genes that correlate with AsA content in tomato fruit have been identified through the use of an algorithm designed to draw functional associations among differentially expressed genes. These possible associations are discussed in terms of the physiological processes that might ultimately regulate the AsA content in tomato fruits, and by mining Arabidopsis expression data repositories we identify cues that may be triggering expression changes similar to those associated with the AsA content in red tomato fruits.

\section{Results and discussion}

\section{Identification of tomato RILs with contrasting content of} AsA in ripe fruits

A population of 158 Recombinant Inbred Lines (RILs) (F8) generated from an inter-specific cross of the domesticated species Solanum lycopersicum cv. Moneymaker (MM) and the wild species Solanum pimpinellifollium (accession TO-937) has been evaluated for AsA content in two consecutive years (Figure 1). Pericarp tissue from at least three red ripe fruits per plant and three plants per genotype were evaluated for AsA content using High Performance Liquid Chromatography (HPLC). Figure 1 shows the distribution of AsA contents in the RIL population when expressed as fresh weight (FW) and dry weight (DW) for two years harvests. As expected, a continuous AsA content distribution was observed due to the polygenic nature of AsA accumulation [22,23]. Table 1 shows the AsA content in the parental and the range in the RILs over the two years evaluated.

Similar to previous reports on another tomato wild relative S. pennelli [22], the AsA content of S. pimpinellifollium was higher than that of the cultivated tomato $S$. lycopersicum MM by about 2-fold on a fresh weight basis (FW), and increased to around 6-fold when expressed as dry weight (DW) (Table 1). The AsA content was lower in both parents in the year 2005 and the same was true for the RILs when expressed on a FW basis indicating an important environmental influence in this trait (Table 1 and Figure 1). Thus, AsA content ranged from $15.9 \mathrm{mg} / 100 \mathrm{~g}$ FW to $56.8 \mathrm{mg} / 100 \mathrm{~g}$ FW in the year 2005 and from $18.0 \mathrm{mg} / 100 \mathrm{~g}$ FW to $74.0 \mathrm{mg} /$ $100 \mathrm{~g} \mathrm{FW}$ in the year 2006 (Figure 1 and Table 1). AsA content in the population remained significantly -although weakly- stable as assessed for repeatability by the correlation coefficient $(\rho=0.29 ; p$-value $=0.0003)$. However, when results were expressed relative to DW, the range of AsA remained approximately the same but the AsA content in most of the RILs were not consistent during both years $(\rho=0.18$; $p$-value $=0.021)$.

Figure 2 depicts the ten RILs lines with the most extreme values of AsA based on the AsA/FW values consistently obtained for the two years. A two-way ANOVA with data from the ten RILs selected and the parents 'Moneymaker' MM and TO-937, using "Genotype" and "Year" as factors, reported significant effect of Genotype $(\mathrm{P}<0.001)$ and Year $(\mathrm{P}<0.001)$ and no significant interaction between them $(\mathrm{P}=0.33)$ (Table 2). The Genotype explained almost $83 \%$ of the variance [(Sum of Squares of Genotype/ Sum of Squares Total)*100 $=(1.97 \mathrm{E} 4 /$ $2.38 \mathrm{E} 4) * 100=82.77 \%]$ validating the selection of these ten RILs for further analysis (Table 2).

\section{Identification of Genes whose expression correlated with AsA content in tomato fruits}

Next, we aimed to identify tomato genes whose expression correlated with the AsA content in red ripe fruits

Table 1 Average AsA content in the parents of the RILs, S. lycopersicum cv. Moneymaker and S. pimpinellifollium acc. TO-937

\begin{tabular}{|c|c|c|c|c|}
\hline \multirow[t]{2}{*}{ Accession } & \multicolumn{2}{|l|}{ AsA - Year 2005} & \multicolumn{2}{|l|}{ AsA - Year 2006} \\
\hline & $\mathrm{mg} / 100 \mathrm{~g} \mathrm{FW}$ & $\mathrm{mg} / \mathrm{g} \mathrm{DW}$ & $\mathrm{mg} / 100 \mathrm{~g} \mathrm{FW}$ & $\mathrm{mg} / \mathrm{g}$ DW \\
\hline Moneymaker (S. lycopersicum) & $14.67 \pm 2.83$ & $0.67 \pm 0.08$ & $20.22 \pm 1.76$ & $1.21 \pm 0.22$ \\
\hline TO-937 (S. pimpinellifollium) & $33.01 \pm 3.33$ & $2.34 \pm 0.74$ & $42.45 \pm 8.29$ & $7.02 \pm 2.31$ \\
\hline RILs Range & $15.92 \pm 3.54-56.81 \pm 21.85$ & $1.01 \pm 0.28-7.56 \pm 0.91$ & $18.01 \pm 8.03-74.01 \pm 8.21$ & $1.60 \pm 0.68-7.16 \pm 2.40$ \\
\hline
\end{tabular}

Range in the RIL population progeny expressed as Fresh (FW) and Dry weight (DW). 


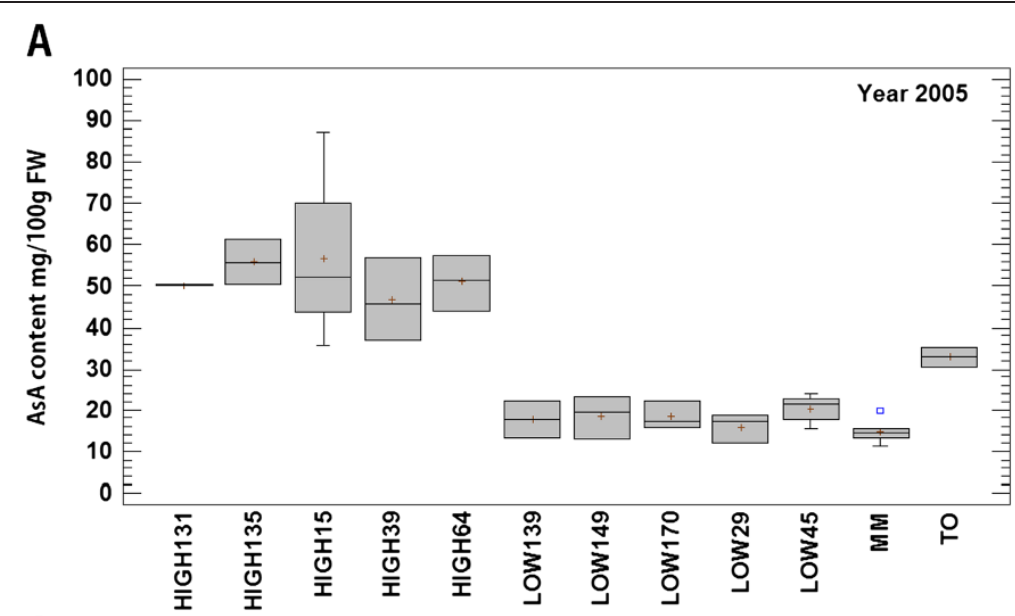

B

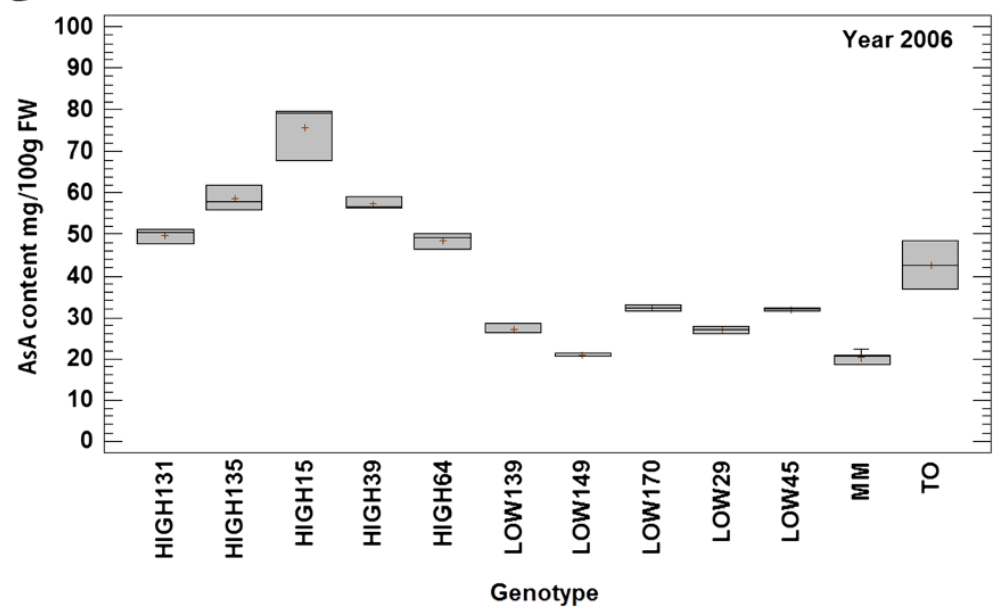

Figure 2 Fruit AsA content in ten contrasting RILs selected for microarray analysis in harvest 2005 (A) and 2006 (B) and the parents Solanum lycopersicum cv. Moneymaker (MM) and Solanum pimpinellifollium acc. TO-937 (TO). Box-and-Whisker plots were drawn extending from the lower quartile of the sample to the upper quartile covering $50 \%$ of data values. The horizontal line represents the median and the plus sign represent the sample mean. The blue square represents an outlier.

from the ten RILs previously selected. For that purpose, differential transcript abundance was analyzed using two-color hybridizations and the TOM2 array (13056 spots), in which according to the unigene set \#3 of the

Table 2 Analysis of Variance for AsA content of ten RILs that comprise the High and Low sets of contrasting lines

\begin{tabular}{llllll}
\hline Source & $\begin{array}{l}\text { Sum of } \\
\text { Squares }\end{array}$ & DF & $\begin{array}{l}\text { Mean } \\
\text { Square }\end{array}$ & F-Ratio* & P-Value \\
\hline Main Effects & & & & & \\
\hline G:Genotype & $1.97 \times 10^{4}$ & 11 & $1.79 \times 10^{3}$ & 40.25 & 0.0000 \\
\hline Y:Year & 971.0 & 1 & 971.0 & 21.86 & 0.0000 \\
\hline Interactions & & & & & \\
\hline G XY & 575.0 & 11 & 52.3 & 1.18 & 0.3269 \\
\hline Error & $2.22 \times 10^{3}$ & 50 & 44.4 & & \\
\hline Total (corrected) & $2.38 \times 10^{4}$ & 73 & & & \\
\hline
\end{tabular}

*All F-ratios are based on the residual mean square error. - Type III Sums of Squares.
Sol Genomic Network (SGN; http://solgenomics.net/) 12,020 tomato sequences are represented [30].

Probes were obtained from: the five individual RILs that contained high AsA, the five individual RILs that contained low AsA, plus two probes generated with a mix of the five of each set. Three biological replicates were hybridized and normalized using as a common reference a sample containing a bulk RNA including all high and low AsA content RILs, and dye-swap was performed. Our analysis resulted in the identification of a number of genes whose expression profile correlated with the high or low AsA content in the 10 RILs (Figure 2).

Using a strict criteria in the Significant Analysis of Microarray (SAM; using a $d=1.3$ and a fold-change threshold of 1 , using a matrix of $\mathrm{Z}$-score values) we identified 137 genes with at least 2-fold change in expression between RILs having high and low AsA content 
(see methods). Forty-four Positive Vitamin $C$ coregulated $(P V C)$ genes (i.e. showing high expression in high-AsA RILs and low expression in low AsA RILs) and 93 Negative Vitamin $C$ co-regulated (NVC) genes (i.e. highly expressed in low-AsA RILs and with low expression in high-AsA RILs) were identified (Additional file 1). In order to validate the microarray results, QRT-PCRs were performed in one of each group of two contrasting RILs for several genes showing differential expression in the microarray (Additional file 2). The QRT-PCR expression of the selected genes was in accordance with microarray data and followed the same trends in the individual lines analyzed.

\section{Functional classification of the PVC and NVC genes}

The 137 differentially expressed genes were classified by functional categories according to the GO slim tool available in the Tomato Expression Database (Figure 3). The functional categorization of the $44 P V C$ genes showed that 8 genes were classified as nucleotide binding, 5 genes encoded proteins showing homology to kinases, and 4 genes encoded putative transporters. Among the 93 NVC genes, 6 were classified as transcription factors, 4 were classified as kinases, and one as a transporter (Figure 3).

The tomato TOM2 microarray contains oligonucleotides against 18 genes encoding for enzymes of the Wheeler-Smirnoff pathway, the main AsA biosynthetic pathway in tomato [31] and for all 5 genes involved in
AsA recycling. Our results fail to identify among the differentially expressed $P V C$ or $N V C$ candidates any of the above-mentioned genes indicating a lack of coregulation between the AsA metabolic pathway and the AsA content in red tomato fruits from our RIL population (Additional file 1). This result is in accordance with a previous study showing that AsA biosynthetic genes are not the main regulators of AsA content in red tomato fruit [27,31]. However, we cannot discard that genes involved in AsA biosynthesis or recycling determine the AsA accumulation during the fruit ripening. Nevertheless we paid special attention to biosynthetic genes whose expression has been suggested to control AsA content during ripening such as GPP1 [31], GGP1 and GGP2 [9,32]. However we did not find any differential expression of these genes that might account for the reported content in AsA among the RILs, indicating that their expression do not determine the final AsA content in tomato fruit in the genetic background of our RILs population. MDHR3, involved in AsA recycling, has been previously reported as a likely candidate for being QTL for AsA content in tomato fruit in studies with the $S$. pennellii IL population $[23,33]$. However, it was not identified as differentially expressed in the RIL population here analyzed. Therefore, whether the genes regulating AsA content are species-dependent or the result of polymorphisms eventually resulting in differences in enzymatic activity deserves further investigation.
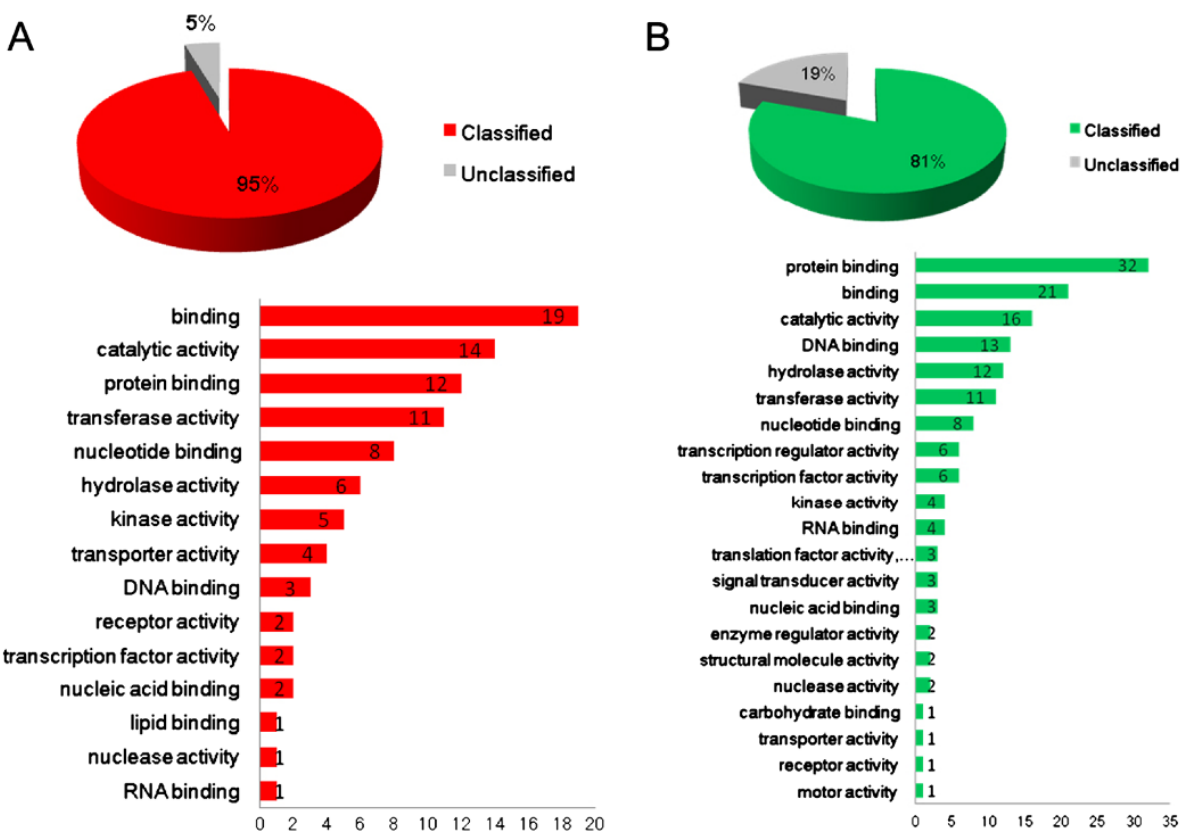

Figure 3 Functional analyses of the genes upregulated in the group of high AsA containing RILs. A) Percentage of annotated unigenes. B) Functional categorization of genes according to the Tomato Expression Database (TED). Numbers on bars represent the number of genes in this category. 
Based on our results we hypothesize that the genetic factors determining the final AsA content in ripe tomato fruits in our RIL population could be the result of altered expression of genes other than AsA biosynthesis, and the analysis of the functional categories classification from the $P V C$ and $N V C$ genes should help us to identify those genes.

\section{Clustering of co-regulated genes using a Self-Organizing Tree Algorithm SOTA}

In order to identify relationships among differentially expressed genes and the AsA content in tomato we performed a Self-Organizing Tree Algorithm (SOTA) [34] using Pearson as metrics. These analyses grouped the transcript abundance profiles in 11 clusters: 4 clusters grouped the 44 PVC genes (Figure 4A) and 7 clusters grouped the 93 NVC genes (6 clusters shown in Figure $4 \mathrm{~B}$ ). The identity of the genes belonging to each cluster is shown in Table 3, which also includes the Unigene annotation based on the Sol Genomic Networks web site (http://solgenomics.net), and the corresponding Arabidopsis ortholog identified using Blast2go [35]. Next, we analyzed in more detail the identity and relationships among members belonging to individual $P V C$ and $N V C$ clusters.

Among the genes found in Cluster 1 there were two with homology to $A B I$ genes (U220589 and U221533), a guanylate kinase, and an ethylene responsive chitinase $B$ [36] (Figure 5A, Table 3). ABI genes encode protein phosphatases $2 \mathrm{C}$ ( $\mathrm{PP} 2 \mathrm{C})$ that are negative regulators of ABA responses through their binding and dephosphorylation of SnRK2, a core component of the cytoplasmic ABA receptors $[37,38]$. The connection between ABA and AsA has been previously established because concomitant upregulation of $\mathrm{ABI} 2$ and enzymes from the ascorbate-glutathione cycle has been recently reported in ABA-treated A. thaliana [39].

Cluster 2 contains two auxin-regulated proteins, one of them, the Aux/IAA transcription factor SlAA3 (SGNU219999) shows an ethylene ripening-associated expression pattern [40], and its transcript accumulation is dramatically reduced in the tomato ripening mutants rin, nor, and $\mathrm{Nr}$ [41]. The rin, nor, and $\mathrm{Nr}$ mutants lack the capacity to respond to the autocatalytic production of ethylene and to further undergo normal ethylene-regulated ripening processes [41]. Therefore, it has been proposed that, ethylene modulates auxin responsiveness during tomato fruit ripening through SlAA3 [40]. The second auxin regulated protein is the Xyloglucan endotransglucosylase-hydrolase-3 (XET3) gene which is expressed during fruit ripening and its expression peaks at the red stage concomitantly with the maximum of ethylene production [42]. The second auxin regulated protein is the Xyloglucan endotransglucosylase-hydrolase-3 (XET3) gene which is expressed during fruit ripening and its expression peaks at the red stage concomitantly with the maximum of ethylene production [42].

Clusters 3 and 4 were closely related and grouped elements that likely have a direct role in the accumulation of AsA such as an ascorbate peroxidase, a putative chloroplastic glutathione reductase, two glutathione-Stransferases (GST), and several kinases. The up-regulation of a putative glutathione reductase together with the consumption of AsA (given the up-regulation of detoxifying enzymes requiring AsA such as GSTs) suggests that the high AsA RILs could also have higher AsA recycling rates. These results contrast with a previous study reporting that a putative ascorbate peroxidase and a putative glutathione$\mathrm{S}$-transferase genes were down-regulated in an inbred line selected for its high AsA content when compared with the parental line [27]. The different results derived from both studies suggest that AsA recycling rate and AsA content might be uncoupled events in the tomato RILs here employed.

The 93 genes down-regulated in the RILs group with the highest content of AsA could be grouped in 7 clusters (Figure 5B, Table 3 and Additional file 1). Cluster 5 includes the $S$. lycopersicum 1-aminocyclopropane-1carboxylate (ACC) oxidase gene (SGN-U214919), whose product is an enzyme involved in ethylene biosynthesis that uses AsA as a cofactor. The silencing of the ACC oxidase gene in tomato is responsible for up to $87 \%$ reductions of ethylene in ripening fruits $[43,44]$. The ACC oxidase down-regulation together with the concomitant down-regulation of a bHLH transcription factor Ethylene Responsive 33 (ER33, SGN-U215556 and SGN-U215557) found in the same cluster seems to point to a reduced ethylene production in the RILs with higher AsA content. This is further supported by the down-regulation of a gene coding for a S. lycopersicum squamosa promoter binding-like (SPBL, SGN-U218217) protein in Cluster 8, and the S. lycopersicum green ripelike 1 (GRL1; SGN-U217197) in Cluster 9. SPBL is the gene affected in the tomato Colorless nonripening $(\mathrm{Cnr})$ mutant that results in colorless fruits with a substantial loss of cell-to-cell adhesion [45]. GRL1 encodes for the closest homolog in tomato of the Green Ripe gene responsible for the non-ripening phenotype found in the dominant Green-ripe (Gr) tomato mutant [46]. Both, $S P B L$ and GRL1 are thought to be involved in ethylene responses during tomato fruit ripening, being major regulatory elements in the network controlling the process. In order to discard possible differences in the ripening stage between the two groups of contrasting AsA genes that could account for the differential expression of ethylene-related genes we searched for their expression pattern during ripening in the Tomato Expression Database (TED, http://ted.bti.cornell.edu/) or in the literature. 


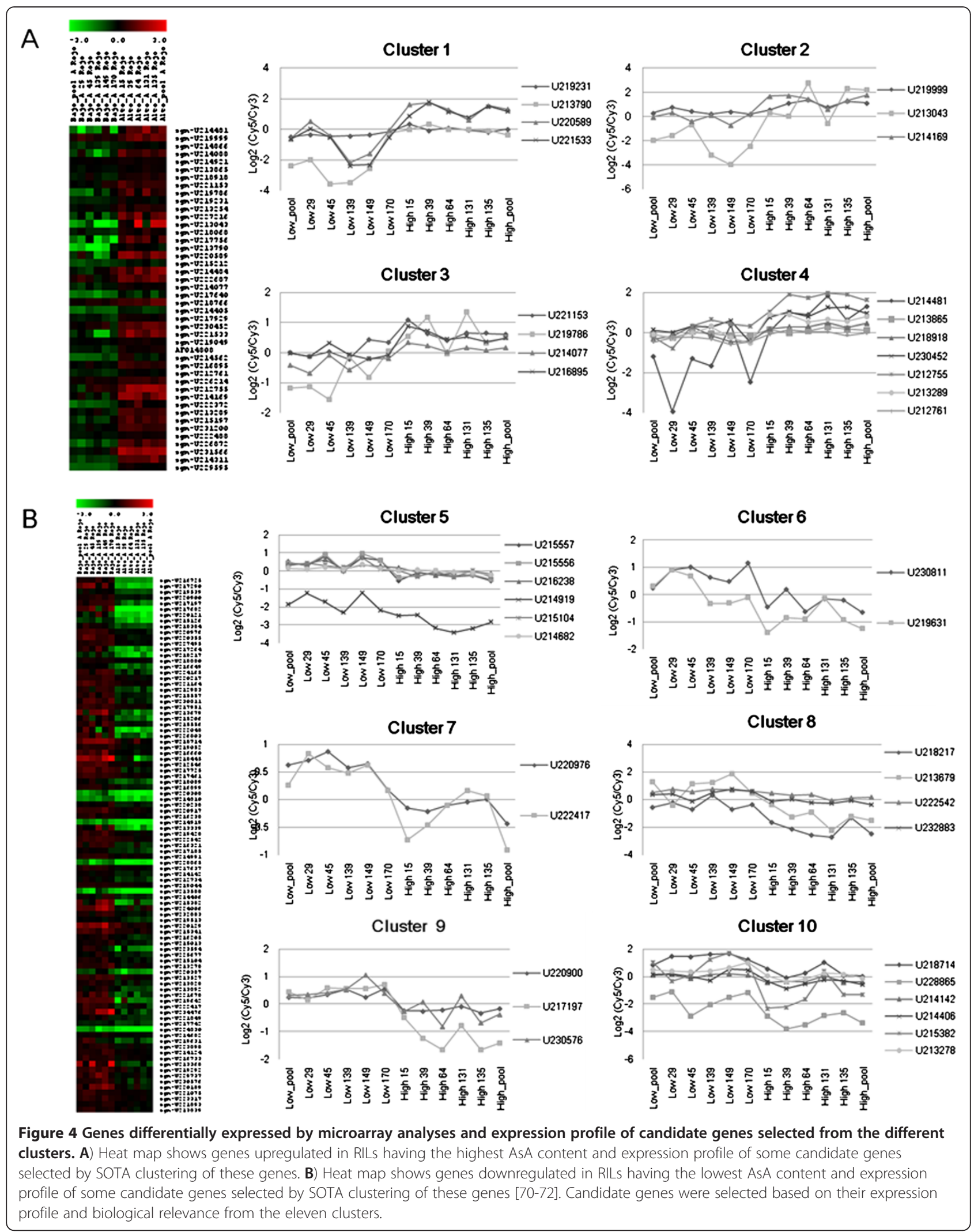


Table 3 Differentially expressed grouped by clusters obtained through SOTA analysis

\begin{tabular}{|c|c|c|c|c|c|}
\hline CLUSTER & SGN_ID \#3 & SGN_ID \#2 & ANNOTATION & TAIR9_BEST_MATCH & SGN_LOCI \\
\hline CLUSTER1 & U213790 & U581507 & acidic extracellular $26 \mathrm{kD}$ chitinase & AT3G12500.1 (1e-74) & Z15141 \\
\hline CLUSTER1 & U219231 & U584749 & adenylate kinase 1 , putative & AT5G63400.1 (8e-113) & None. \\
\hline CLUSTER1 & U220589 & U585017 & $\mathrm{ABI} 2$, protein phosphatase $2 \mathrm{c}$, putative & AT3G11410.1 (1e-27) & None. \\
\hline CLUSTER1 & U221533 & U585018 & $\mathrm{ABI}$, protein phosphatase $2 \mathrm{c}$, putative & AT3G11410.1 (3e-66) & None. \\
\hline CLUSTER2 & U213043 & U579445 & $\begin{array}{l}\text { Solanum lycopersicum xyloglucan endotransglucosylase- } \\
\text { hydrolase XTH3 }\end{array}$ & AT4G25810.1 (6e-113) & xth3 \\
\hline CLUSTER2 & U214169 & U574723 & putative auxin-regulated protein & AT2G28150.1 (6e-19) & None. \\
\hline CLUSTER2 & U219999 & U577993 & Solanum lycopersicum auxin-regulated IAA3 (IAA3) & AT5G43700.1 (3e-57) & iaa3 \\
\hline CLUSTER3 & U214077 & U581654 & ascorbate peroxidase, putative & AT4G35000.1 (6e-126) & None. \\
\hline CLUSTER3 & U216895 & U576606 & ATP-binding protein serine-threonine kinase, putative & AT5G42440.1 (4e-96) & None. \\
\hline CLUSTER3 & U219786 & U580500 & WRKY-type DNA binding protein, putative & AT5G13080.1 (2e-45) & None. \\
\hline CLUSTER3 & U221153 & U571305 & protein kinase, putative & AT3G09830.2 (5e-54) & None. \\
\hline CLUSTER4 & U212755 & U581433 & glutathione-S-transferase, putative & AT3G09270.1 (3e-52) & None. \\
\hline CLUSTER4 & U212761 & U581313 & rieske iron-sulfur protein-like, putative & AT5G13430.1 (9e-109) & None. \\
\hline CLUSTER4 & U213289 & U568366 & guanylate kinase 1 , putative & AT3G57550.2 (9e-118) & None. \\
\hline CLUSTER4 & U213865 & U577749 & glutathione reductase, putative & AT3G24170.1 (0) & None. \\
\hline CLUSTER4 & U214481 & U579446 & Glutathione-S-transferase, putative & AT1G78380.1 (8e-86) & None. \\
\hline CLUSTER4 & U218918 & U577701 & Gibberellin 3-beta-dioxygenase $2-3$, putative & AT1G52820.1 (9e-19) & None. \\
\hline CLUSTER4 & U230452 & U575457 & Receptor-like protein kinase 5 , putative & AT3G57120.1 (2e-44) & None. \\
\hline CLUSTER5 & U214682 & U576104 & MYB-CC type transcription factor, putative & AT2G01060.1 (4e-75) & None. \\
\hline CLUSTER5 & U214919 & U577773 & $\begin{array}{l}\text { Solanum lycopersicum 1-aminocyclopropane-1-carboxylate } \\
\text { oxidase }\end{array}$ & AT1G05010.1 (3e-132) & EF501822 \\
\hline CLUSTER5 & U215104 & U578524 & Rac-like GTP-binding protein, putative & AT4G35020.1 (7e-95) & None. \\
\hline CLUSTER5 & U215556 & U575819 & Solanum lycopersicum ER33 protein & AT1G05710.3 (2e-39) & er33 \\
\hline CLUSTER5 & U215557 & U575819 & Solanum lycopersicum ER33 protein & AT1G05710.3 (2e-39) & er33 \\
\hline CLUSTER5 & U216238 & U586247 & $\begin{array}{l}\text { ASKdZeta (Arabidopsis SHAGGY-related protein kinase dZeta), } \\
\text { putative }\end{array}$ & AT2G30980.1 (0) & SISK \\
\hline CLUSTER6 & U219631 & U581955 & Solanum lycopersicum gibberellin 20-oxidase-3 & AT4G25420.1 (8e-138) & AF049900 \\
\hline CLUSTER6 & U230811 & U563226 & tetratricopeptide repeat-containing protein, putative & AT1G33400.1 (3e-59) & None. \\
\hline CLUSTER7 & U220976 & U572513 & F-box protein GID2, putative & AT4G24210.1 (2e-21) & None. \\
\hline CLUSTER7 & U222417 & U566338 & bZip family Transcription factor, putative & AT5G65210.2 (3e-116) & None. \\
\hline CLUSTER8 & U213679 & U575872 & Solanum lycopersicum ETAG-A3 & AT2G01850.1 (2e-131) & ETAG-A3 \\
\hline CLUSTER8 & U218217 & U570030 & Solanum lycopersicum squamosa promoter binding-like protein & AT2G33810.1 (3e-33) & None. \\
\hline CLUSTER8 & U232883 & U594117 & gigantea, putative & AT1G22770.1 (4e-28) & None. \\
\hline CLUSTER9 & U217197 & U586453 & Solanum lycopersicum green ripe-like 1 & AT2G26070.1 (8e-87) & grrl1 \\
\hline CLUSTER9 & U220900 & U566888 & UDP-sugar transporter, putative & AT4G32272.1 (5e-136) & None. \\
\hline CLUSTER10 & U213278 & U580739 & $\begin{array}{l}\text { CBL-interacting serine/threonine-protein kinase (cipk3), } \\
\text { putative }\end{array}$ & AT2G26980.3 (0) & None. \\
\hline CLUSTER10 & U214406 & U585891 & cellulose synthase, putative & AT5G05170.1 (0) & None. \\
\hline CLUSTER10 & U215382 & U580011 & BR1, XET1 (xyloglucan endo-transglycosylase precursor) & AT3G23730.1 (2e-121) & br1 \\
\hline CLUSTER10 & U228865 & U564048 & cytochrome P450, putative & AT5G24910.1 (1e-55) & None. \\
\hline
\end{tabular}

Unigene annotations based on the Sol Genomic Networks web site (http://solgenomics.net), and the accession numbers corresponding to Arabidopsis orthologs identified using Blast2go [35] are shown for those genes whose expression is depicted in Figure 4.

For instance, according to TED, the expression of S. lycopersicum 1-aminocyclopropane-1-carboxylate (ACC) oxidase gene (SGN-U214919) does not vary significantly between breaker and red stage. On the other hand, it has been reported that the expression of ER33 (SGN-U215556 and SGN-U215557) is induced in red stage and does not vary from mature green to turning [47], so if the differential expression were due to differences in the ripening stage, they should have occurred in all RILs from one group, something highly unlikely. These data allowed us to discard differences in ripening stages as the source of differential expression in ethylene-related genes. 


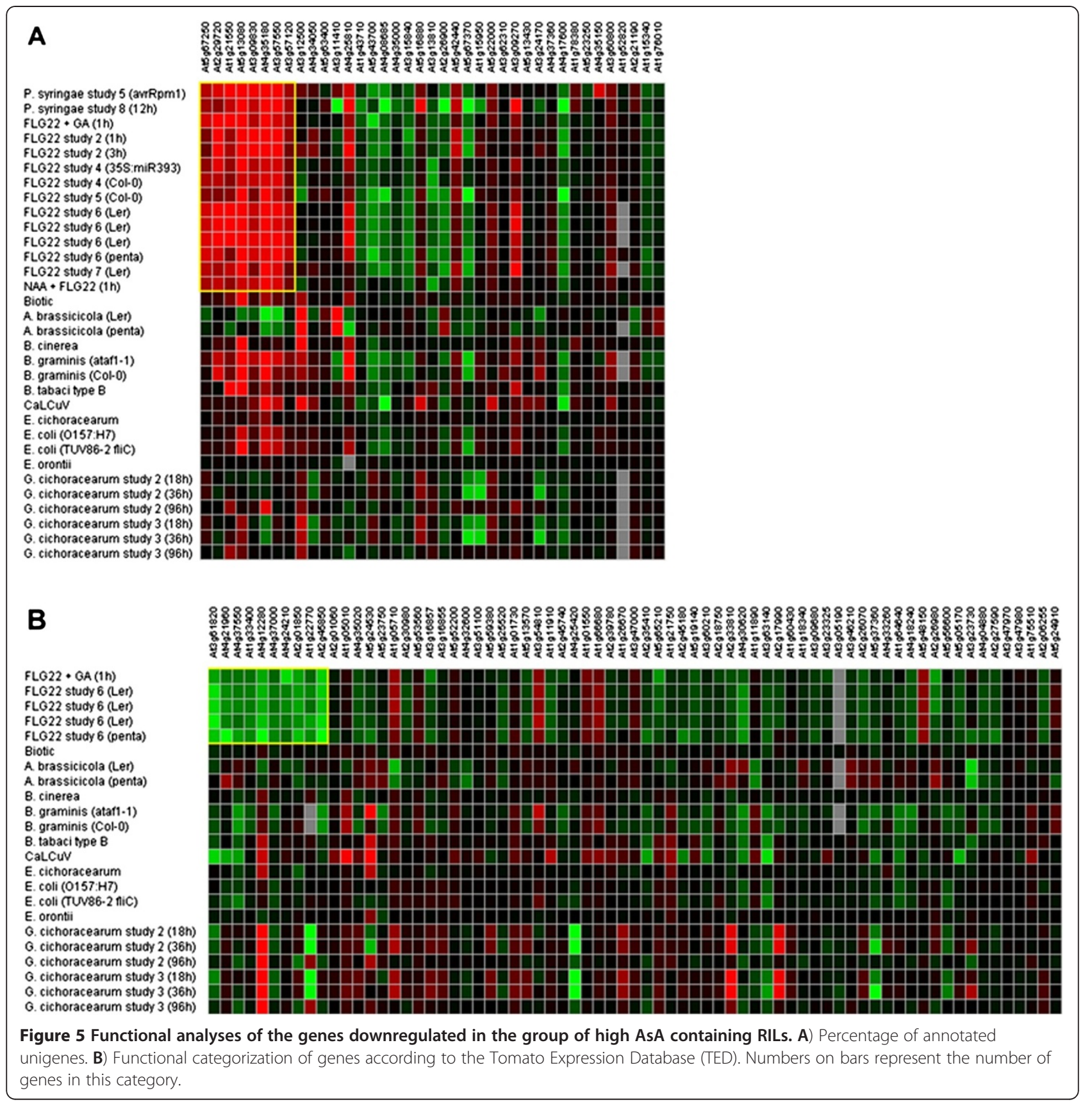

Clusters 6 and 7 include different elements involved in the responses to gibberellins, such as the S. lycopersicum gibberellin 20-oxidase-3 gene and the putative GID2 Fbox gene. The Gibberellin 20-oxidase-3 is one of the three GA 20-oxidases (GA 20-ox) involved in the 13hydroxilation gibberellin biosynthesis pathway. In this pathway, the intermediate $\mathrm{GA}_{12}$ is converted to $\mathrm{GA}_{20}$, to be subsequently hydroxilated to the bioactive $\mathrm{GA}_{1}$ form by GA 3-ox [48]. GA 20-oxidases are main regulatory control points of the gibberellin biosynthesis pathway [49]. The rice GID2 F-box protein is part of the SCF (SKP1, CDC53, F-box protein)-type E3 ubiquitin ligase
$\mathrm{SCF}^{\mathrm{GID} 2 / \mathrm{SLY} 1}$ that positively regulates gibberellin signaling through the degradation of specific DELLA repressors $[50,51]$. The differential regulation of genes implicated in gibberellin biosynthesis, with positive correlation of GA-3 ox in Cluster 4 and negative correlation of GA-20 ox in Cluster 6 is remarkable, opening the possibility that GA influences, points to a nonpreviously described interaction between gibberellin and AsA content in tomato.

Cluster 9 contains a gene encoding for a putative UDP-sugar transporter (SGN-U220900) (Figure 4B and Table 3). How AsA transport occurs between 
compartments of the cell and the apoplast remains largely unknown, as well as the transport of the several intermediates for its synthesis [52]. In many cases, NDP-sugars involved in AsA biosynthesis, such as UDP-glucose, UDP-glucuronic acid and GDP-mannose, are available in the cytosol, and likely require specific transporters to pass through the endomembrane system for further processing. The dow-nregulation of an UDPsugar transporter in the RILs containing more AsA might be indicative of the importance of NDP-sugar transporters in the final content of AsA in a plant tissue.

Cluster 10 groups two cell wall related genes, a putative cellulose synthase and a xyloglucan endotransglycosylase precursor SIXET1 induced by brassinoesteroids [53]. Other cell wall modifying enzyme, the S. lycopersicum endoxyloglucan transferase (EXGT-A3), was identified in Cluster 8. This result might reveal a link between cell wall modification, degradation, and AsA content [3]. Normally, SIXET1 appears strongly down-regulated at the beginning of turning stage of fruit ripening and appears undetectable at the red stage [42], in contrast to SIXET3 (up-regulated in this study) whose expression drops at the turning and pink stages, to raise again at the red stage. Finally, a putative cytochrome P450 whose expression pattern resembles that of SIXET1 was also identified in Cluster 10. Cytochromes P450, many of which are involved in the biosynthesis and metabolism of brassinosteroids [54], are known to control the redox status of the cell [55]. The fact that several elements controlling the plant redox status were identified in our analysis lead us to hypothesize that this process might be determinant for the AsA accumulation in tomato fruit (Figure 6).

\section{Genes correlated with AsA content in tomato fruit are regulated by oxidative stress}

Databases for co-expression analysis have been established for the model plant Arabidopsis thaliana, which can be used to get insights into the mechanisms underlying the differential transcript abundance in our contrasting AsA lines. As result, various repositories of transcriptome data are now available including NASCArrays, [5] GEO, [6] SMD, [7] ArrayExpress, [8] and AtGenExpress, [9-11], which collectively provide 6,100 microarray data points (7 September 2011). Using this repository, we have searched for the most homologous $P V C$ and $N V C$ genes in Arabidopsis (AtPVC and $A t N V C$, respectively), and we have analyzed using a correlation analysis of the clustering tools in Genevestigator V3 [56] whether different experimental conditions were reported to cause the transcriptional induction or repression of these sets of genes.
The results of our co-expression datasets were analyzed independently for $P V C$ and $N V C$ genes using this huge data set repository. We were expecting that if the $P V C$ and $N V C$ set of genes have a collective biological significance they must be regulated by similar conditions in an opposite way. We identified that $25.6 \%$ of the AtPVC genes were induced by flagellin22 (flag22) (Figure 4A). Importantly, we found that $15.5 \%$ of $A t N V C$ genes were repressed by flag 22 treatment in an independent correlation analysis (Figure 4B). The fact that independent correlation analyses using AtPVC and AtNVC genes rendered similar treatments in Arabidopsis clearly indicates that these are relevant biological associations.

Early events caused by flag22 treatments include ion fluxes across the plasma membrane and the formation of reactive oxygen species $[57,58]$. This relationship of $P V C$ and $N V C$ genes with a ROS-generating agent adds further support to the association of AsA content and the maintenance of the redox state, as deduced from the clustering analysis.

\section{Conclusion}

The differentially expressed genes that correlate with AsA content in tomato fruits identified in the present study suggest a scenario where several genes involved in hormone responses are interlinked to modulate the content of AsA (Figure 6). Cross-talk among different hormones has been reported to regulate several processes in plants: gibberellins and auxin in tomato fruit set [48,49,59]; gibberellins and ABA during seed germination [49,60]; gibberellins and ethylene, in root elongation [49,61]; ABA and ethylene, in the modulation the overall carbon status during early seedling growth and development [62]; brassinosteroids and auxin in the control of lateral root growth [63], etc. Ethylene has been implicated indirectly in the regulation of reduced AsA content in pericarp prior to tomato ripening as the ethylene-insensitive $\mathrm{Nr}$ mutant accumulates almost 2fold AsA compared to wild type during Mature green and Breaker stages [26]. ABA has also been connected with the increase of AsA content through promoting its recycling [39]. The co-regulation analyses in Arabidopsis using the $P V C$ and $N V C$ orthologs identified that these genes are similarly regulated by flag 22 , whose primary effect is the generation of ROS in response to pathogen attack $[57,58]$. These results suggest that AsA content in tomato fruit might be critically regulated by hormone interactions, and it is directly related to the oxidative status of the fruit, as previously suggested [64]. However an important aspect that needs to be considered is the likely possibility that part of the AsA in the tomato fruit as has been recently reported. Therefore part of the fruit AsA, in addition of in situ biosynthesis, is likely to be 


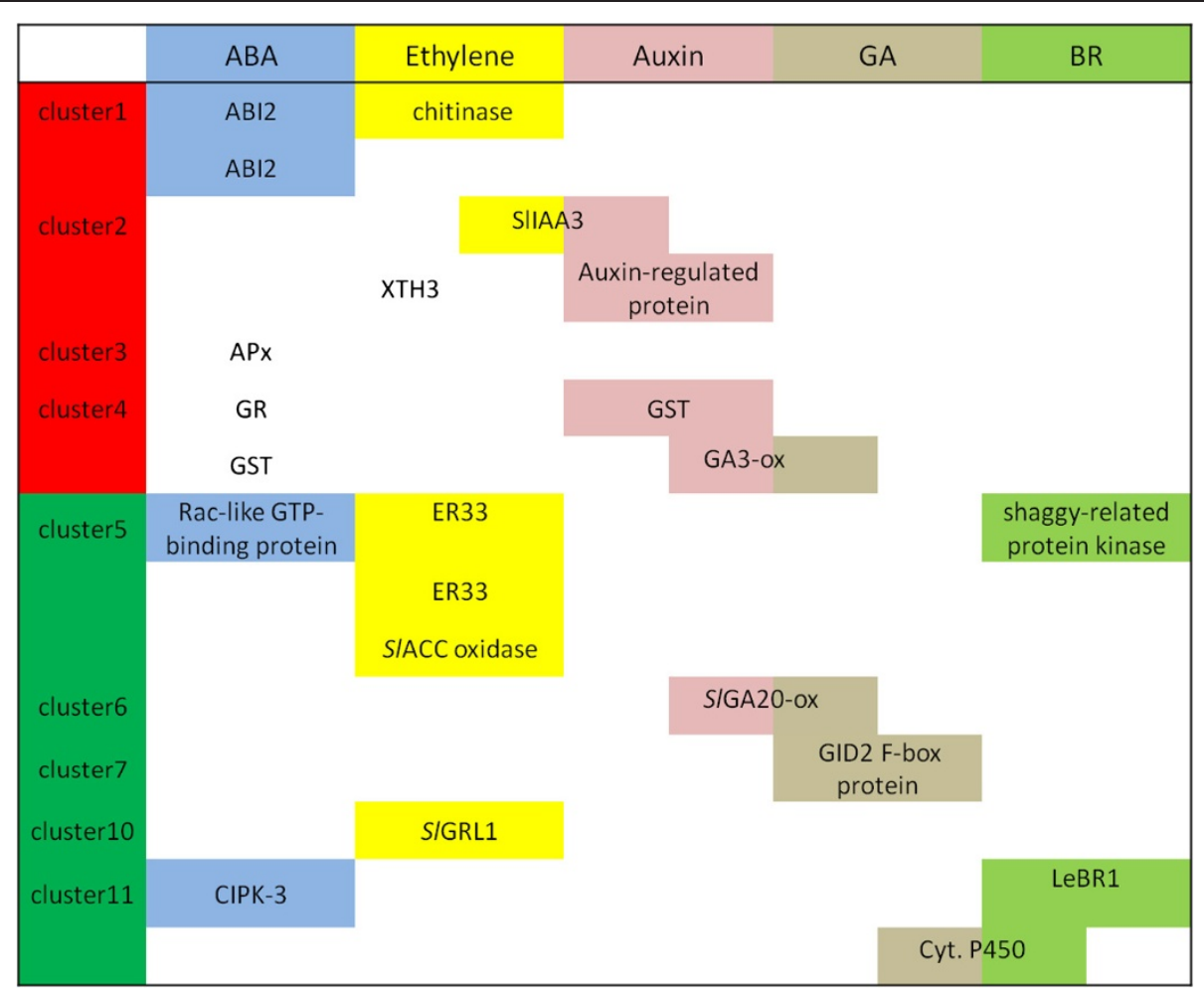

Figure 6 Diagram of hormone-related candidate genes. The candidate genes known to be related to hormone pathways are depicted with a color code and according to their cluster. Genes probably related to a hormone pathway are depicted under the hormone column but without background color. Genes in boxes sharing two colors correspond to those located at interlinking hormone pathways. Clusters with red background are those grouping genes upregulated in RILs showing the high AsA content and those with green background correspond to those grouping downregulated genes in the same RILs. Gene names are in Table 3. APx, Ascorbate Peroxidase; CIPK-3: calcineurin B-like-interacting protein kinase 3; Cyt. P450: cytochrome P450; ER33: Ethylene responsive 33; GA3-ox: Gibberellin 3 oxidase; SIGA20-ox:; S. Iycopersicum Gibberellin 20 oxidase; GST: Glutathione-S-transferase; GR, Glutathione Reductase; LeBR1: Lycopersicum esculentum brasinoesteroid-regulated xyloglucan endo-transglycosylase 1; SIACC: S. lycopersicum 1-aminocyclopropane-1-carboxylate; SIGRL1: Green ripe-like 1; SIIAA3: Aux/IAA transcription factor 3; XTH3: Xyloglucan endotransglucosylase-hydrolase-3.

provided by source organs complicating even more the identification of AsA determinants [65].

Current approaches have been unfruitful in explaining the natural variability of AsA content in tomato fruit. The combination of different omics approaches, surveying several metabolites, genes, and gene products seems to be the most realistic way of finding out the source(s) of complex traits like AsA content, whose variation among different tomato species is intricately related with hormones $[26,39,66]$. The exhaustive analyses of the omics data provides a more rational picture of the actual physiological processes determining the AsA fruit content, and would allow to target sets of co-expressed genes to be further studied by functional analyses.

\section{Methods}

\section{Plant material}

A population of 158 Recombinant Inbred Lines (RILs) generated between an inter-specific cross of Solanum lycopersicum cv. Moneymaker (MM) and Solanum pimpinellifollium (acces. TO-937) were cultivated in a multi tunnel polyethylene greenhouse as well as the parental plants. RILs were generated by repeated selfing of an F2 generation to reach the $F_{8}$ generation by single seed descent procedure. Fruits in red ripe stage were collected during two harvests, in June 2005 and late spring of 2006. Only fruits from trusses 3-4 were collected and during the same time lapse and hour of the day to minimize environmental fluctuations that could affect AsA content. Three independent samples from each RIL and at least three fruits per plant were collected in the harvest 2005 while a pool from all biological replicates was made in harvest 2006. In the first harvest (2005) the fruits were picked at the breaker stage and were kept at room temperature until reaching the light red stage, sliced and immediately frozen in liquid nitrogen and stored at $-80^{\circ} \mathrm{C}$ until analyzed. On the other hand, fruits from the second harvest (2006) were picked at light red stage. Visual inspection was used to cull obvious variants (typically, fruits with peel cracking 
and showing Yellow Shoulder Disorder as well as parthenocarpic fruit).

\section{Microarray experiments}

Microarray experiments were carried out at Fruit Genomics and Biotechnology lab of the Instituto de Biologia Molecular y Celular de Plantas. Normalization and curation of microarray data was carried out at the Computer Architecture and the Laboratorio de Bioquímica y Biotecnología Vegetal, Universidad de Malaga.

\section{RNA Extraction and microarray hybridization}

Ten out of 158 tomato RILs (S. lycopersicum cv. Moneymaker x S. pimpinellifollium accession. TO-937) were selected based on their extreme pericarp AsA content (the five with lowest and the five with highest contents) in the harvest 2005 to perform expression analyses. Data were confirmed with harvest 2006. Three replicates per RIL were assayed.

RNA extraction was performed as described previously [67]. RNA amplification and aminoallyl labeling was performed with MessageAmp ${ }^{\mathrm{TM}}$ aRNA kit (Ambion) according to manufacturer indications. The AminoAllyl aRNA dye coupling and purification was performed using Megaclear Kit and fragmentation was achieved using RNA Fragmentation Reagents (Ambion) following manufacturer instructions.

For expression analyses a tomato microarray $(13,056$ spots) was employed (see details at http://www.ibmcp. upv.es).

Each of the RILs RNA as well as two pools, each one comprised of the low- and high-AsA content RILs (Low-pool and High-pool; respectively), was hybridized individually against a control made of the pool of all contrasting RILs (both low- and high-AsA content). The experimental design included a dye-swap, and images were obtained with the GenePix Pro 6.0.

\section{Scanning, data acquisition, filtering, and processing}

Expression signal data were read and processed with the standalone software Prep +07 [68]. All scan acquisitions were performed at normal intensity (PMT GAIN $=730 \mathrm{~V} \times 610 \mathrm{~V}$ ) with a minimal number of saturated signals (less than $0.55 \%$ in all cases). The protocol used in this study includes empty spots that contain a solution of DMSO $50 \%$ in order to maintain the rest of values unaltered. Technical replicates were merged into a single data by using the estimated median of their signals, excluding those replicates with a high standard deviation. Data were preprocessed in order to obtain log-ratios following by the filtering of low quality data and the normalizing with Lowess. Differential expression was calculated through the mean and standard deviations of the spot distribution of $\log _{2}$ (ratio) values, and also defining a global fold change difference and confidence, equivalent to a z-test [68].

The microarray data analyses were performed with TIGR Multiple Experiment Viewer Software v4.6 (http://www. tm4.org) [34] using an expression matrix of 7,351 spots with two or less missing values. KNN impute [69] was used to approximate missing values. Differentially-expressed transcripts were obtained using SAM (Significant Analysis of Microarray) [69], implemented as described previously (http://www-stat.stanford.edu/ tibs/SAM/) using a $d=1.3$ and a fold-change threshold of 1 (as data is represented in a $\log _{2}$ of fold difference, it represents a 2 -fold change in expression). A valuable feature of SAM is that it gives estimates of the False Discovery Rate (FDR), which is the proportion of genes likely to have been identified by chance as being significant [70]. Furthermore, SAM is an interactive algorithm that allows the user to eyeball the distribution of the test statistic, and then set thresholds for significance (through the tuning parameter delta) after looking at the distribution [70]. In our experiment, using $d=1.3$ allowed us to select 137 genes with a false rate of 4 genes. Expression profiles were clustered using a Self-Organizing Tree Algorithm [71-73] following Pearson coefficient as metrics and establishing a p-value of 0.05. Blast2GO (http://blast2go.bioinfo.cipf.es/) was used to provide automatic high-throughput annotation, gene ontology (GO) mapping, and categorization of unigenes showing differential expression [35]. Sequences whose annotation was not automatically provided through similarity matching in the NCBI non-redundant NR database, Interpro, or SwissPro databases were annotated according to the Sol Genomic Network database (http://solgenomics.net). In each case, an expectation value threshold of $10^{-10}$ was used. Functional categorization of genes was performed with the GO slim tool of the Tomato expression database (http://ted.bti. cornell.edu/cgi-bin/TFGD/array/funcat.cgi).

\section{Statistical analyses}

Statistical analyses were performed using Statgraphics Centurion XVI and Microsoft Excel. Interaction between the factors "Year" and "Genotype" was assessed through a twoway ANOVA. Significant differences in the means of ascorbic acid content among the selected RILs and the parental lines were determined using ANOVA and Least Significant Difference (LSD) as post-hoc test.

\section{CDNA synthesis and QRT- PCR}

Total RNA extracted was used to synthesize singlestranded cDNA using the M-MLV reverse transcriptase (RNase $\mathrm{H}$ depleted, Promega $\mathrm{GmbH}$ ) and oligo(dT) primer according to the manufacturer's instructions. The PCR amplification was performed with gene-specific primers (Table: List of GOI and the primers used for PCR amplification for cDNA synthesis). GAPDH (glyceraldehyde 3- 
phosphate dehydrogenase, SGN-U212862) and/or gene SGN-U214197 (C1-QRT), not displaying changes in expression according to microarray analysis, were used to normalize QRT- PCR analyses.

The list of GOI and the primers used for PCR amplification for cDNA synthesis have been: SGN-U220976 (Gene3), Fw: 5'-CTACCTCTGGCCACTCTCAA-3', Rv: 5'-AACTTCGTCTTTTCCCCATC-3'; SGN-U226214 (Gene6), Fw: 5'-TGCTCTTTTTGCTTCATTTGG-3, 'Rv: 5'- TGGTACAGGCGATAAAATCCTT-3'; SGN-U220900 (Gene7), Fw:5' - TTTTATGGCTATGCCGTCGT-3', Rv: 5'GGTCCACAGACGATTCCATT-3'; SGN-U213289 (Gene 12), Fw: 5'- ATGGGGTTGATCATGAATTG-3', Rv:5'ATGGGGTTGATCATGAATTG-3'.

The cDNA was amplified using the SYBR-Green PCR Master kit (Applied Biosystems) containing AmpliTaq Gold Polymerase using an iCycler (BioRad) according to the protocol provided by the supplier. QRT- PCR quantification was performed using pBase Plus version $1.5[74,75]$.

\section{AsA determination}

AsA content in fruit tissue was determined by using a High-performance liquid chromatography equipment (Jasco) with a reversed-phase column $\left(\mathrm{Gemini}^{\circledR} 3 \mu \mathrm{m} \mathrm{C18}\right.$ Phenomenex, Inc.; Kromasil C18, Scharlau) with ultraviolet detection $(254 \mathrm{~nm})$. Tomato pericarp was ground to a fine powder in liquid nitrogen and weighted. AsA extraction was as follows: $1 \mathrm{ml}$ of Extraction buffer (2\% m-phosphoric acid, $2 \mathrm{mM}$ EDTA) was added to $0.15 \mathrm{mg}$ of frozen powder. Samples were vortexed till thawing the extraction buffer and were kept on ice for $20 \mathrm{~min}$. They were spun down, filtered and carefully transferred to an HPLC vial to avoid warming out of the sample. The HPLC mobile phase was $0.1 \mathrm{M} \mathrm{NaH}_{2} \mathrm{PO} 4$ and $0.2 \mathrm{mM} \mathrm{Na}_{2}$ EDTA, pH 3.1 adjusted with ortho-phosphoric acid as previously reported [76].

\section{Additional files}

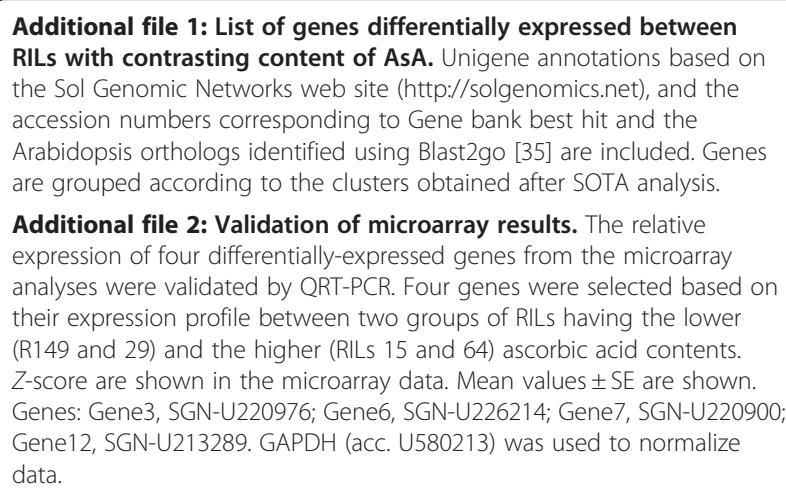

Additional file 2: Validation of microarray results. The relative expression of four differentially-expressed genes from the microarray analyses were validated by QRT-PCR. Four genes were selected based on their expression profile between two groups of RILs having the lower (R149 and 29) and the higher (RILs 15 and 64) ascorbic acid contents. $Z$-score are shown in the microarray data. Mean values \pm SE are shown. Genes: Gene3, SGN-U220976; Gene6, SGN-U226214; Gene7, SGN-U220900; Gene12, SGN-U213289. GAPDH (acc. U580213) was used to normalize data

\section{Competing interests}

The author(s) declare that they have not competing interests.

\section{Authors' contributions}

VL-S carried out the ascorbic acid determination, expression studies by microarrays and QRT-PCR, data analysis and preparation of the manuscript. $A R$, data analysis and preparation of the manuscript. VA-S, Arabidopsis data analysis. AM-M, and OT, data analysis of the microarrays. AG supervised the microarray hybridization and data analysis. RF-M, generated the RILs and collected the samples. $A B$ and $W$, data analysis and preparation of the manuscript. $M A B$, project co-ordination and supervision, preparation of the manuscript. All authors read and approved the final manuscript.

\section{Acknowledgements}

This work was supported by the EUSOL Integrated Project (grant no. FOODCT-2006-016214), ESPSOL proposal (Fundación Genoma España) and by el Ministerio de Ciencia e Innovación (MICINN), co-financed by the European Regional Development Fund (FEDER) (grant BIO2011-23859). The authors thank Dr. Paola E. Leone and Dr. Atilio Deana for helping in manuscript writing and Sophie Mirabel for technical support during the microarray hybridization. Part of this work was accomplished with help from European Molecular Biology Organization short-term fellowship.

\section{Author details}

${ }^{1}$ Instituto de Hortofruticultura Subtropical y Mediterránea, Universidad de Málaga-Consejo Superior de Investigaciones Científicas (IHSM-UMA-CSIC), Departamento Biología Molecular y Bioquímica, Universidad de Málaga, 29071, Málaga, Spain. ²BioFIG - Center for Biodiversity, Functional \& Integrative Genomics, Departamento de Biologia, Universidade do Minho, Campus de Gualtar, Braga, Portugal. ${ }^{3}$ Computer Architecture Department, University of Malaga, Campus de Teatinos, 29071, Málaga, Spain. ${ }^{4}$ Instituto de Biología Molecular y Celular de Plantas, Consejo Superior delnvestigaciones Científicas, Universidad Politécnica de Valencia, 46022, Valencia, Spain. ${ }^{5}$ Boyce Thompson Institute for Plant Research, Tower Road, Ithaca, NY 14853, USA. ${ }^{6}$ Instituto de Hortofruticultura Subtropical y Mediterránea, Universidad de Málaga-Consejo Superior de Investigaciones Científicas (IHSM-UMA-CSIC), Est. Exp. La Mayora, Algarrobo-Costa, Málaga, Spain. ${ }^{7}$ Departamento de Biología Molecular y Bioquímica, Universidad de Málaga, Málaga, Spain.

Received: 7 December 2011 Accepted: 25 April 2012

Published: 14 May 2012

\section{References}

1. Davey MW, Montagu MV, Inzé D, Sanmartin M, Kanellis A, Smirnoff N, Benzie IJJ, Strain JJ, Favell D, Fletcher J: Plant L-ascorbic acid: chemistry, function, metabolism, bioavailability and effects of processing. J Sci Food Agric 2000, 80(7):825-860.

2. Smirnoff N: Ascorbate biosynthesis and function in photoprotection. Philos Trans R Soc Lond B Biol Sci 2000, 355(1402):1455-1464.

3. Valpuesta $V$, Botella MA: Biosynthesis of L-ascorbic acid in plants: new pathways for an old antioxidant. Trends Plant Sci 2004, 9(12):573-577.

4. Fairfield KM, Fletcher $\mathrm{RH}$ : Vitamins for chronic disease prevention in adults: scientific review. JAMA 2002, 287(23):3116-3126.

5. Li Y, Schellhorn HE: New developments and novel therapeutic perspectives for vitamin C. J Nutr 2007, 137(10):2171-2184

6. Nyyssonen K, Parviainen MT, Salonen R, Tuomilehto J, Salonen JT: Vitamin C deficiency and risk of myocardial infarction: prospective population study of men from eastern Finland. BMJ 1997, 314(7081):634-638.

7. Agius F, Gonzalez-Lamothe R, Caballero JL, Munoz-Blanco J, Botella MA, Valpuesta $\mathrm{V}$ : Engineering increased vitamin $\mathrm{C}$ levels in plants by overexpression of a D-galacturonic acid reductase. Nat Biotechnol 2003, 21(2):177-181.

8. Alhagdow M, Mounet F, Gilbert L, Nunes-Nesi A, Garcia V, Just D, Petit J, Beauvoit B, Fernie AR, Rothan $C$, et al: Silencing of the mitochondrial ascorbate synthesizing enzyme L-galactono-1,4-lactone dehydrogenase affects plant and fruit development in tomato. Plant Physiol 2007, 145(4):1408-1422.

9. Bulley SM, Rassam M, Hoser D, Otto W, Schunemann N, Wright M, MacRae E, Gleave A, Laing W: Gene expression studies in kiwifruit and gene overexpression in Arabidopsis indicates that GDP-L-galactose guanyltransferase is a major control point of vitamin $C$ biosynthesis. J Exp Bot 2009, 60(3):765-778.

10. Chen Z, Gallie DR: Dehydroascorbate reductase affects leaf growth, development, and function. Plant Physio/ 2006, 142(2):775-787. 
11. Chen Z, Young TE, Ling J, Chang SC, Gallie DR: Increasing vitamin C content of plants through enhanced ascorbate recycling. Proc Natl Acad Sci U S A 2003, 100(6):3525-3530

12. Eltayeb A, Kawano N, Badawi G, Kaminaka H, Sanekata T, Shibahara T, Inanaga S, Tanaka K: Overexpression of monodehydroascorbate reductase in transgenic tobacco confers enhanced tolerance to ozone, salt and polyethylene glycol stresses. Planta 2007, 225(5):1255-1264.

13. Gatzek S, Wheeler GL, Smirnoff N: Antisense suppression of I-galactose dehydrogenase in Arabidopsis thaliana provides evidence for its role in ascorbate synthesis and reveals light modulated I-galactose synthesis. Plant J 2002, 30(5):541-553.

14. Gilbert L, Alhagdow M, Nunes-Nesi A, Quemener B, Guillon F, Bouchet B, Faurobert M, Gouble B, Page D, Garcia V, et al: GDP-D-mannose 3,5epimerase (GME) plays a key role at the intersection of ascorbate and non-cellulosic cell-wall biosynthesis in tomato. Plant J 2009, 60(3):499-508

15. Hemavathi, Upadhyaya CP, Young KE, Akula N, Kim Hs, Heung JJ, Oh OM, Aswath CR, Chun SC, Kim DH, et al: Over-expression of strawberry d-galacturonic acid reductase in potato leads to accumulation of vitamin C with enhanced abiotic stress tolerance. Plant Sci 2009, 177(6):659-667.

16. Keller R, Renz FS, Kossmann J: Antisense inhibition of the GDP-mannose pyrophosphorylase reduces the ascorbate content in transgenic plants leading to developmental changes during senescence. Plant J 1999 19(2):131-141.

17. Lorence A, Chevone BI, Mendes P, Nessler CL: Myo-inositol oxygenase offers a possible entry point into plant ascorbate biosynthesis. Plant Physiol 2004, 134(3):1200-1205.

18. Endres S, Tenhaken R: Myoinositol oxygenase controls the level of myoinositol in Arabidopsis, but does not increase ascorbic acid. Plant Physiol 2009, 149(2):1042-1049.

19. Endres S, Tenhaken R: Down-regulation of the myo-inositol oxygenase gene family has no effect on cell wall composition in Arabidopsis. Planta 2011

20. Frary A, Nesbitt TC, Grandillo S, Knaap E, Cong B, Liu J, Meller J, Elber R, Alpert KB, Tanksley SD: fw2.2: a quantitative trait locus key to the evolution of tomato fruit size. Science 2000, 289(5476):85-88.

21. Fridman E, Carrari F, Liu YS, Fernie AR, Zamir D: Zooming in on a quantitative trait for tomato yield using interspecific introgressions. Science 2004, 305(5691):1786-1789.

22. Rousseaux MC, Jones CM, Adams D, Chetelat R, Bennett A, Powell A: QTL analysis of fruit antioxidants in tomato using Lycopersicon pennellii introgression lines. Theor App/ Genet 2005, 111(7):1396-1408.

23. Stevens R, Buret M, Duffe $P$, Garchery C, Baldet $P$, Rothan C, Causse M: Candidate genes and quantitative trait loci affecting fruit ascorbic acid content in three tomato populations. Plant Physiol 2007, 143(4):1943-1953.

24. Garcia V, Stevens R, Gil L, Gilbert L, Gest N, Petit J, Faurobert M, Maucourt M, Deborde C, Moing A, et al: An integrative genomics approach for deciphering the complex interactions between ascorbate metabolism and fruit growth and composition in tomato. C R Biol 2009, 332(11):1007-1021.

25. Mounet F, Moing A, Garcia V, Petit J, Maucourt M, Deborde C, Bernillon S, Le Gall G, Colquhoun I, Defernez M, et al: Gene and metabolite regulatory network analysis of early developing fruit tissues highlights new candidate genes for the control of tomato fruit composition and development. Plant Physiol 2009, 149(3):1505-1528.

26. Alba R, Payton P, Fei Z, McQuinn R, Debbie P, Martin GB, Tanksley SD, Giovannoni JJ: Transcriptome and selected metabolite analyses reveal multiple points of ethylene control during tomato fruit development. Plant Cell 2005, 17(11):2954-2965.

27. Di Matteo A, Sacco A, Anacleria M, Pezzotti M, Delledonne M, Ferrarini A Frusciante L, Barone A: The ascorbic acid content of tomato fruits is associated with the expression of genes involved in pectin degradation. BMC Plant Biol 2010, 10:163

28. Aoki K, Ogata Y, Shibata D: Approaches for Extracting Practical Information from Gene Co-expression Networks in Plant Biology. Plant Cell Physiol 2007, 48(3):381-390.

29. Ozaki S, Ogata Y, Suda K, Kurabayashi A, Suzuki T, Yamamoto N, lijima Y, Tsugane T, Fujii T, Konishi $C$, et al: Coexpression analysis of tomato genes and experimental verification of coordinated expression of genes found in a functionally enriched coexpression module. DNA Res 2010, 17(2):105-116.
30. Martin-Requena V, Munoz-Merida A, Claros MG, Trelles O: PreP + 07: improvements of a user friendly tool to preprocess and analyse microarray data. BMC Bioinformatics 2009, 10(1):16.

31. Loannidi E, Kalamaki MS, Engineer C, Pateraki I, Alexandrou D, Mellidou I, Giovannonni J, Kanellis AK: Expression profiling of ascorbic acid-related genes during tomato fruit development and ripening and in response to stress conditions. J Exp Bot 2009, 60(2):663-678.

32. Li M, Ma F, Liang D, Li J, Wang Y: Ascorbate biosynthesis during early fruit development is the main reason for its accumulation in kiwi. PLoS One 2010, 5(12):e14281.

33. Stevens R, Page D, Gouble B, Garchery C, Zamir D, Causse M: Tomato fruit ascorbic acid content is linked with monodehydroascorbate reductase activity and tolerance to chilling stress. Plant Cell Environ 2008, 31(8):1086-1096.

34. Saeed Al, Sharov V, White J, Li J, Liang W, Bhagabati N, Braisted J, Klapa M, Currier T, Thiagarajan M, et al: TM4: a free, open-source system for microarray data management and analysis. Biotechniques 2003, 34(2):374-378

35. Conesa A, Gotz S, Garcia-Gomez JM, Terol J, Talon M, Robles M: Blast2GO: a universal tool for annotation, visualization and analysis in functional genomics research. Bioinformatics 2005, 21(18):3674-3676.

36. Lin Z, Arciga-Reyes L, Zhong S, Alexander L, Hackett R, Wilson I, Grierson D: SITPR1, a tomato tetratricopeptide repeat protein, interacts with the ethylene receptors NR and LeETR1, modulating ethylene and auxin responses and development. J Exp Bot 2008, 59(15):4271-4287.

37. Ma Y, Szostkiewicz I, Korte A, Moes D, Yang Y, Christmann A, Grill E: Regulators of PP2C phosphatase activity function as abscisic acid sensors. Science 2009, 324(5930):1064-1068.

38. Park SY, Fung P, Nishimura N, Jensen DR, Fujii H, Zhao Y, Lumba S, Santiago J, Rodrigues A, Chow TF, et al: Abscisic acid inhibits type 2 C protein phosphatases via the PYR/PYL family of START proteins. Science 2009, 324(5930):1068-1071.

39. Ghassemian M, Lutes J, Chang HS, Lange I, Chen W, Zhu T, Wang X, Lange BM: Abscisic acid-induced modulation of metabolic and redox control pathways in Arabidopsis thaliana. Phytochemistry 2008, 69(17):2899-2911.

40. Chaabouni S, Jones B, Delalande C, Wang H, Li Z, Mila I, Frasse P, Latche A, Pech JC, Bouzayen M: SI-IAA3, a tomato Aux/IAA at the crossroads of auxin and ethylene signalling involved in differential growth. J Exp Bot 2009, 60(4):1349-1362.

41. Giovannoni JJ: Fruit ripening mutants yield insights into ripening control. Curr Opin Plant Biol 2007, 10(3):283-289.

42. Miedes E, Lorences EP: Xyloglucan endotransglucosylase/hydrolases (XTHs) during tomato fruit growth and ripening. J Plant Physiol 2009, 166(5):489-498.

43. Mirica LM, Klinman JP: The nature of $\mathrm{O} 2$ activation by the ethyleneforming enzyme 1-aminocyclopropane-1-carboxylic acid oxidase. Proc Natl Acad Sci U S A 2008, 105(6):1814-1819.

44. Hamilton AJ, Lycett GW, Grierson D: Antisense gene that inhibits synthesis of the hormone ethylene in transgenic plants. Nature 1990 346(6281):284-287.

45. Manning $K$, Tor M, Poole M, Hong Y, Thompson AJ, King GJ, Giovannoni JJ, Seymour GB: A naturally occurring epigenetic mutation in a gene encoding an SBP-box transcription factor inhibits tomato fruit ripening. Nat Genet 2006, 38(8):948-952.

46. Barry CS, Giovannoni JJ: Ripening in the tomato Green-ripe mutant is inhibited by ectopic expression of a protein that disrupts ethylene signaling. Proc Natl Acad Sci U S A 2006, 103(20):7923-7928.

47. Zegzouti H, Jones B, Frasse P, Marty C, Maitre B, Latch A, Pech JC, Bouzayen $\mathrm{M}$ : Ethylene-regulated gene expression in tomato fruit: characterization of novel ethylene-responsive and ripening-related genes isolated by differential display. Plant J 1999, 18(6):589-600.

48. de Jong M, Mariani C, Vriezen WH: The role of auxin and gibberellin in tomato fruit set. J Exp Bot 2009, 60(5):1523-1532.

49. Weiss $D$, Ori $N$ : Mechanisms of cross talk between gibberellin and other hormones. Plant Physiol 2007, 144(3):1240-1246.

50. Gomi K, Sasaki A, Itoh H, Ueguchi-Tanaka M, Ashikari M, Kitano H, Matsuoka M: GID2, an F-box subunit of the SCF E3 complex, specifically interacts with phosphorylated SLR1 protein and regulates the gibberellindependent degradation of SLR1 in rice. Plant J 2004, 37(4):626-634.

51. Schwechheimer C: Understanding gibberellic acid signaling-are we there yet? Curr Opin Plant Biol 2008, 11(1):9-15. 
52. Horemans $\mathrm{N}$, Foyer $\mathrm{CH}$, Asard $\mathrm{H}$ : Transport and action of ascorbate at the plant plasma membrane. Trends Plant Sci 2000, 5(6):263-267.

53. Koka CV, Cerny RE, Gardner RG, Noguchi T, Fujioka S, Takatsuto S, Yoshida S, Clouse SD: A putative role for the tomato genes DUMPY and CURL-3 in brassinosteroid biosynthesis and response. Plant Physiol 2000, 122(1):85-98.

54. Ohnishi T, Yokota T, Mizutani M: Insights into the function and evolution of P450s in plant steroid metabolism. Phytochemistry 2009, 70(17-18):1918-1929.

55. Divi UK, Rahman T, Krishna P: Brassinosteroid-mediated stress tolerance in Arabidopsis shows interactions with abscisic acid, ethylene and salicylic acid pathways. BMC Plant Biol 2010, 10:151.

56. Zimmermann P, Hirsch-Hoffmann M, Hennig L, Gruissem W: GENEVESTIGATOR. Arabidopsis microarray database and analysis toolbox. Plant Physiol 2004, 136(1):2621-2632.

57. Asai T, Tena G, Plotnikova J, Willmann MR, Chiu WL, Gomez-Gomez L, Boller T, Ausubel FM, Sheen J: MAP kinase signalling cascade in Arabidopsis innate immunity. Nature 2002, 415(6875):977-983.

58. Zipfel C, Robatzek S, Navarro L, Oakeley EJ, Jones JD, Felix G, Boller T: Bacterial disease resistance in Arabidopsis through flagellin perception. Nature 2004, 428(6984):764-767.

59. Serrani JC, Ruiz-Rivero O, Fos M, Garcia-Martinez JL: Auxin-induced fruit-set in tomato is mediated in part by gibberellins. Plant J 2008, 56(6):922-934.

60. Gomez-Cadenas A, Zentella R, Walker-Simmons MK, Ho TH: Gibberellin/ abscisic acid antagonism in barley aleurone cells: site of action of the protein kinase PKABA1 in relation to gibberellin signaling molecules. Plant Cell 2001, 13(3):667-679.

61. Achard P, Vriezen WH, Van Der Straeten D, Harberd NP: Ethylene regulates arabidopsis development via the modulation of DELLA protein growth repressor function. Plant Cell 2003, 15(12):2816-2825.

62. Gazzarrini S, McCourt P: Genetic interactions between ABA, ethylene and sugar signaling pathways. Curr Opin Plant Biol 2001, 4(5):387-391.

63. Bao F, Shen J, Brady SR, Muday GK, Asami T, Yang Z: Brassinosteroids interact with auxin to promote lateral root development in Arabidopsis. Plant Physiol 2004, 134(4):1624-1631.

64. Jimenez A, Creissen G, Kular B, Firmin J, Robinson S, Verhoeyen M Mullineaux P: Changes in oxidative processes and components of the antioxidant system during tomato fruit ripening. Planta 2002, 214(5):751-758.

65. Badejo AA, Wada K, Gao Y, Maruta T, Sawa Y, Shigeoka S, Ishikawa T: Translocation and the alternative D-galacturonate pathway contribute to increasing the ascorbate level in ripening tomato fruits together with the D-mannose/L-galactose pathway. J Exp Bot 2012, 63(1):229-239.

66. Wolucka BA, Goossens A, Inze D: Methyl jasmonate stimulates the de novo biosynthesis of vitamin C in plant cell suspensions. J Exp Bot 2005, 56(419):2527-2538.

67. Bugos RC, Chiang VL, Zhang XH, Campbell ER, Podila GK, Campbell WH: RNA isolation from plant tissues recalcitrant to extraction in guanidine. Biotechniques 1995, 19(5):734-737.

68. Martin-Requena V, Munoz-Merida A, Claros MG, Trelles O: PreP + 07: improvements of a user friendly tool to preprocess and analyse microarray data. BMC Bioinformatics 2009, 10:16.

69. Troyanskaya O, Cantor M, Sherlock G, Brown P, Hastie T, Tibshirani R, Botstein D, Altman RB: Missing value estimation methods for DNA microarrays. Bioinformatics 2001, 17(6):520-525.

70. Tusher VG, Tibshirani R, Chu G: Significance analysis of microarrays applied to the ionizing radiation response. Proc Natl Acad Sci U S A 2001, 98(9):5116-5121.

71. Dopazo J, Carazo JM: Phylogenetic Reconstruction Using an Unsupervised Growing Neural Network That Adopts the Topology of a Phylogenetic Tree. J Mol Evol 1997, 44(2):226-233.

72. Herrero J, Dopazo J: Combining hierarchical clustering and selforganizing maps for exploratory analysis of gene expression patterns. J Proteome Res 2002, 1(5):467-470

73. Herrero J, Valencia A, Dopazo J: A hierarchical unsupervised growing neural network for clustering gene expression patterns. Bioinformatics 2001, 17(2):126-136.

74. Hellemans J, Mortier G, De Paepe A, Speleman F, Vandesompele J: qBase relative quantification framework and software for management and automated analysis of real-time quantitative PCR data. Genome Biol 2007, 8(2):R19.
75. Vandesompele J, De Preter K, Pattyn F, Poppe B, Van Roy N, De Paepe A, Speleman F: Accurate normalization of real-time quantitative RT-PCR data by geometric averaging of multiple internal control genes. Genome Biol 2002, 3(7):RESEARCH0034.

76. Harapanhalli RS, Howell RW, Rao DV: Testicular and plasma ascorbic acid levels in mice following dietary intake: a high-performance liquid chromatographic analysis. J Chromatogr 1993, 614(2):233-243.

doi:10.1186/1471-2164-13-187

Cite this article as: Lima-Silva et al.: Genetic and genome-wide transcriptomic analyses identify co-regulation of oxidative response and hormone transcript abundance with vitamin $\mathrm{C}$ content in tomato fruit. BMC Genomics 2012 13:187.

\section{Submit your next manuscript to BioMed Central and take full advantage of:}

- Convenient online submission

- Thorough peer review

- No space constraints or color figure charges

- Immediate publication on acceptance

- Inclusion in PubMed, CAS, Scopus and Google Scholar

- Research which is freely available for redistribution 